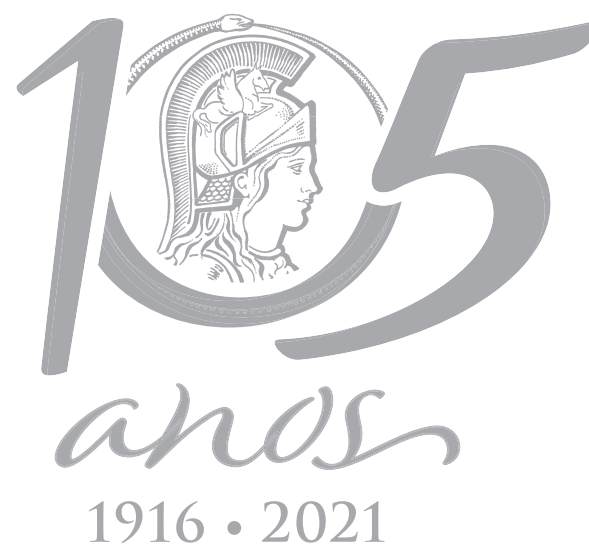

\title{
Gender-related differences in the modulation of anthropometric, biochemical, and immune markers by physical activity in hypertensive and diabetic individuals
}

\author{
DÉBORAH C. DOS SANTOS, ISRAEL S. RIBEIRO, DIEGO PATRICK S. LOPES, ITTALO \\ S. PEREIRA, DENISAR P. SANTOS, IGOR P.R. MUNIZ, FERNANDA M. DA SILVA LIMA, \\ ANDRESSA ANTÔNIA S. COSTA, DANIELA DA SILVA P. SOUZA, STÉFANO PEDRO DE \\ MELO CALADO, CAROLINE V. GONÇALVES, MARIA POLIANA L. GALANTINI, DANILO \\ N. LOPES, ROBSON A.A. DA SILVA \& GILVANÉIA S. SANTOS
}

\begin{abstract}
Systemic arterial hypertension (SAH) and type 2 diabetes mellitus (T2DM) compose the two major noncommunicable chronic inflammatory diseases. Physical activity has been shown as a promising complementary approach to control the systemic inflammation. However, it is still unclear whether this modulation is genderdependent. The objective of this study was evaluate the gender-related influence of physical activity on the inflammatory response and biochemical profile of individuals with SAH and T2DM. An international physical activity questionnaire was applied to 376 individuals diagnosed with SAH and T2DM in order to access their exercises routine and was evaluated the influence of physical activity in biochemical, anthropometrical, and immunological markers involved in these disorders in men and women. Even though active individuals have exhibited lower serum levels of IL-1 $\beta$, IFN- $\gamma$, TNF- $\alpha$, and IL-17A, the ratios between IL-10 and all inflammatory cytokines were higher in men than in women. Physically active individuals also demonstrated increased HDL/LDL and HDL/ VLDL ratios. Moreover, multiple correlations revealed that in active women both IL-10 and TNF- $\alpha$ serum levels positively correlate with fasting glucose levels, and were negatively associated with HDL levels. Our findings suggest that gender-related differences dictate a distinct crosstalk between inflammatory and biochemical markers in physically active individuals.
\end{abstract}

Key words: Systemic arterial hypertension, gender, inflammation, physical activity, type 2 diabetes mellitus.

\section{INTRODUCTION}

Over the years, chronic noncommunicable diseases have been assuming an important role in health-related concerns, and nowadays, they represent themajor affecting disorders for the world population (Prince et al. 2015). It is known that, in elderlies, cardiovascular diseases, systemic arterial hypertension, cancer, and diabetes mellitus are the most common pathologies, causing a lower quality of life to these individuals, besides higher assistance costs, and lower life expectancy (Marengoni et al. 2008, Prince et al. 2015). Studies have also been demonstrating an augment in prevalence of chronic noncommunicable diseases in young adults, raising the need to include them in population studies (Chen et al. 2011, Kissela 
et al. 2012). Overall, they present more severe prognoses as they grow older (Smajlović 2015).

Systemic arterial hypertension (SAH) stands out as a chronic multifactorial disease, being one of the main causes of cardiovascular diseases and stroke (Nag \& Ghosh 2013). It affects about $25 \%$ of the world's adult population and it is estimated that by 2025 this picture will rise up to $29 \%$ (Mittal \& Singh 2010). SAH is usually associated with other chronic conditions such as type 2 diabetes mellitus (T2DM), a metabolic disorder characterized by the inability of insulin in performing its functions (Cheung \& Li 2012).

Both conditions have their pathogenesis related to chronic low-grade inflammation, defined by the release of pro-inflammatory cytokines such as TNF- $\alpha$ and low levels of regulatory cytokines such as IL-10 (Aroor et al. 2012, Zhong et al. 2014). Researches have reported that, besides immunological factor, body composition can infer the health-disease state of individuals (Sagun et al. 2014, Ribeiro et al. 2019).

The practice of physical activity has been proposed as an important therapeutic approach for diabetic and hypertensive individuals ( $\mathrm{Hu}$ et al. 2004, Trachta et al. 2014). It is already known that exercise induces HDLC production, an important protective molecule in this condition (Zhou et al. 2014). Furthermore, works have revealed that people who exercise have beneficial anti-inflammatory modulation, even in overweight and obese individuals (Lopes et al. 2016). However, men and women have physiological differences that are crucial in inflammatory modulation between different genders, which is an important variable that must be considered when carrying out studies in the biomedical and health-related areas (Wizemann \& Pardue 2001). Such differences are not limited to hormonal aspects. This is clear in studies in which men with reduced levels of testosterone and that were supplemented with estradiol at levels similar to those of women in the luteal phase had completely different inflammatory responses (Timmons et al. 2006). This fact demonstrates the importance of studies that consider different parameters and multifactorial analyzes, in order to obtain a real understanding of gender differences and how they influence the applied therapeutic platforms. Therefore, in this study, we sought to evaluate the gender-related influence of physical activity on the inflammatory response and biochemical profile of individuals with SAH and T2DM.

\section{MATERIALS AND METHODS}

\section{Ethical considerations}

This project was approved by the Human Research Ethics Committee of Federal University of Bahia under the protocol number 27439114.4.0000.5556.

\section{Study population}

This study comprised the evaluation of 376 adult individuals of both genders, aging between 30 to 80 yearsold, that had been diagnosed with $\mathrm{SAH}$ and T2DM and assisted by Family Health Units (USF) of Vitória da Conquista, Bahia, Brazil. Data collection was performed in the Health Units, participation was voluntary, and the sample size was defined by convenience.

The assessment initially consisted of an explanation of research subject and scope, and afterwards, those who agree in participating had to signed the Informed Consent Form and/or performed finger print identification. Later, the semi-structured questionnaire on socioeconomic data and physical activity practice was applied and anthropometric evaluation, analysis of the estimation of body composition by bioimpedance, blood pressure measurement, 
and blood collection for biochemical and cytokines measurements were carried out.

\section{Sample classification}

For this study, the cutoff point used for patients practicing physical activity (PA) was thereference values indicated by the IPAQ (Matsudo et al. 2001). Active patients were classified as practicing physical activity in a frequency greater than or equal to one hundred and fifty minutes per week ( $\geq 150$ minutes/week) taking into account recreational, sports, physical exercise, and leisure activities. Sedentary patients were classified as people who did not exercise the volume of weekly physical activities to be classified as active.

\section{Criteria for inclusion or exclusion}

The inclusion criterionminimum age of 30 and maximum of 80 years oldwere applied to the volunteers, who had not physical activityimpairment or musculoskeletal injuries, and who had been exercising for at least three months. This information was acquired through a sociodemographic questionnaire, self-reported by the participants. The exclusion criteria were to have been diagnosed of autoimmune diseases and/or use of anti-inflammatory drugs.

\section{Anthropometric evaluation}

Anthropometric measures of weight and height, body mass index (BMI), waist circumference (WC), and WC/height ratio were collected to characterize participants' nutritional status. Weight determination was accomplished using a digital weight balance coupled to bioimpedance (Plenna, SP, Brazil) previously calibrated in the Nutritional Assessment Laboratory of Federal University of Bahia. Bioimpedance measurements were performed providing the fat mass, lean mass, bone mass, body water, and basal metabolism data.
For bioimpedance data to be as reliable as possible, some recommendations were suggested to participants and they weredo not consume alcoholic beverages and/or containing caffeine, fast for four hours, do not perform physical activity the day before the test, drink water two hours before the examination and urinate at least thirty minutes before performing the bioimpedance device.

\section{Arterial pressure assessment}

Blood pressure was measured through an automatic digital pressure device (G-TECH brand, model BP3AA1-1), approved by the Brazilian Society of Cardiology, with individuals sitting comfortably for at least 5 minutes (feet flat on the floor), in a silent environment with the right arm positioned at the level of the heart. For purpose of data analysis, mean values obtained through two blood pressure measurements, carried out at intervals of approximately 10 minutes, were used.

\section{Dosages of biochemical markers}

Previously aware of an 8-hour fasting, five milliliters of peripheral blood were collected in dry vacuum tubes from the volunteers. The tubes were centrifuged at $300 \mathrm{~g}$ for 10 minutes and the plasma stored in Eppendorf tubes in freezer at -70 으 until the time of the experiments for biochemical and immunological analyzes.

Kits from the manufacturer Bioclin, Minas Gerais, Brazil and manufacturer's specifications for the kits monoreagent cholesterol (K083), enzymatic HDL (K015), monoreagent triglycerides (K117) and monoreagent glucose (K088) were strictly followed.

\section{Quantification of cytokines}

Cytokines concentration (IL-1 $\beta$, TNF- $\alpha$, IL-10, IL-17A and IFN-y) were quantified by ELISA (EnzymeLinked Immunosorbent Assay) according to 
Quantikine manufacturers' recommendations of the respective kits (R\&D Systems).

\section{Statistical analysis}

Data normal distribution was verified by Shapiro-Wilk test. When the variables did not present a normal distribution, the comparisons between the active and sedentary groups were performed by the non-parametric Mann Whitney test. For data that presented normal distribution, Student's t-test (parametric test) was then used. To study the associations among the parameters in this study a correlation matrix was plotted applying the R-package corrplot 0.84 based on Spearman rank correlations with ordering of variables following first principal component analysis (Wei \& Simko 2013).

Statisticalanalysiswas done using GraphPadPrisma Version 6.0 software (GraphPad Software, (A, USA). Numerical variables were expressed as mean \pm standard deviation and the differences considered statistically significant were applied when the value of $p<0.05$, with a confidence interval of $95 \%$.

\section{RESULTS}

\section{Characterization of the most used drugs by the study population}

Among the most common medicines used by the study population, oral antihypertensives, such as hydrochlorothiazide (54\%) and losartan potassium (50\%) were the major rep resentatives. The main oral hypoglycemic drugs were metformin (67\%) and glibenclamide (27\%). The statin class drug simvastatin was prescribed for $37 \%$ of the study sample. There was no statistical difference between men and women groups concerning common medications.

\section{Physically active men presented a different body composition compared to sedentary men and to women}

In this research, physically active men presented lower waist circumference/height ratio (WC/ Height), lower BMI, and more lean mass than sedentary men, and active and sedentary women (Table I). Remarkably, sedentary men presented less fat mass than physically active and sedentary womenand more lean mass than sedentary women.

Interestingly, we were able to detect adifference between the mean systolic blood pressureof sedentary and active women. Such difference was not observed between active and sedentary men (Table I).

\section{Physically active men and women presented a distinct profile of biochemical markers than sedentary men and women}

We were able to detect a higher concentration of $\mathrm{HDL}$ alongside with lower values for LDL, VLDL, glucose, triglycerides, and total cholesterol (Table I) in the serum of individuals (men and women) who practiced physical activity. Furthermore, through the HDL cholesterol and LDL or VLDL fractions ratios, it was observed that individuals engaged in physical activity exhibited higher ratio values than the sedentary ones.

\section{Active men with diabetes and hypertension presented less inflammation than active women}

Individuals serum inflammatory profile was assessed. The inflammation markers profile acquired here has shown to be in consonance with the biochemical data, as the inflammatory cytokines serum concentration (represented by IL-1 $\beta$, TNF- $\alpha$, IL-17 and IFN- $\gamma$ ) were lower, together with a higher level of IL-10 in individuals 
Table I. Characterization of anthropometric, blood pressure data, biochemical and cytokine markers in diabetics and hypertensive individuals.

\begin{tabular}{|c|c|c|c|c|}
\hline Parameters & $\begin{array}{l}\text { Physically active } \\
\text { men } \\
(n=40)\end{array}$ & $\begin{array}{l}\text { Sedentary men } \\
\quad(n=54)\end{array}$ & $\begin{array}{l}\text { Physically active women } \\
\qquad(\mathrm{n}=98)\end{array}$ & $\begin{array}{l}\text { Sedentary women } \\
\quad(n=184)\end{array}$ \\
\hline \multirow[b]{2}{*}{ wC/Height } & 0.5582 & 0.6322 & 0.6181 & 0.6761 \\
\hline & $\begin{aligned} \text { SD: } 0.058 \\
\S\end{aligned}$ & $\begin{array}{c}\text { SD:0.062 } \\
+\end{array}$ & $\begin{array}{c}\text { SD:0.069 } \\
+\end{array}$ & $\begin{array}{c}\text { SD:0.449 } \\
+\end{array}$ \\
\hline \multirow[b]{2}{*}{ BMI $\left(\mathrm{kg} / \mathrm{m}^{2}\right)$} & 25.66 & 29.35 & 27.95 & 30.89 \\
\hline & $\begin{array}{c}\text { SD: } 3.545 \\
\S \neq \emptyset\end{array}$ & $\begin{array}{c}\text { SD: } 4.597 \\
+\end{array}$ & $\begin{array}{c}\text { SD: } 3.673 \\
+\end{array}$ & $\begin{array}{c}\text { SD: } 6.138 \\
+\end{array}$ \\
\hline \multirow[b]{2}{*}{ Leanmass (\%) } & 27.89 & 12.8 & 14.58 & 11.56 \\
\hline & $\begin{array}{l}\text { SD: } 6.538 \\
\S \neq \emptyset\end{array}$ & $\begin{array}{c}\text { SD: } 1.874 \\
+\end{array}$ & $\begin{array}{c}\text { SD: } 5.248 \\
+\end{array}$ & $\begin{array}{c}\text { SD: } 2.727 \\
+\S\end{array}$ \\
\hline \multirow[b]{2}{*}{ Fat mass $(\%)$} & 13.02 & 29.11 & 31.41 & 34.19 \\
\hline & $\begin{array}{l}\text { SD: } 7.413 \\
\S \neq \emptyset\end{array}$ & $\begin{array}{l}\text { SD: } 3.966 \\
\quad † \neq \emptyset\end{array}$ & $\begin{array}{c}\text { SD: } 5.307 \\
+\S\end{array}$ & $\begin{array}{c}\text { SD: } 4.937 \\
+\S\end{array}$ \\
\hline \multirow[b]{2}{*}{ MSP (mmHg) } & 143.3 & 153.3 & 140.7 & 154.9 \\
\hline & SD: 12.73 & $\begin{aligned} \text { SD: } & 22.92 \\
& \neq\end{aligned}$ & $\begin{array}{c}\text { SD: } 10.94 \\
\text { \$ף }\end{array}$ & $\begin{array}{c}\text { SD: } 18.39 \\
\quad \downarrow \neq\end{array}$ \\
\hline \multirow[b]{2}{*}{ Cholesterol (mg/dL) } & 192.9 & 233 & 195.9 & 233.3 \\
\hline & $\begin{array}{c}\text { SD:10.13 } \\
\$ \rrbracket\end{array}$ & $\begin{array}{c}\text { SD: } 36.16 \\
\quad t \neq\end{array}$ & $\begin{array}{c}\text { SD: } 12.65 \\
\S \rrbracket\end{array}$ & $\begin{array}{c}\text { SD: } 40.76 \\
\quad t \neq\end{array}$ \\
\hline \multirow{2}{*}{$\begin{array}{l}\text { Triglycerides (mg/ } \\
\mathrm{dL} \text { ) }\end{array}$} & 123.9 & 196.2 & 131.1 & 196.2 \\
\hline & $\begin{array}{c}\text { SD: } 20.92 \\
\$ \rrbracket\end{array}$ & $\begin{array}{c}\text { SD: } 35.3 \\
\dagger \neq\end{array}$ & $\begin{array}{c}\text { SD: } 21.47 \\
\$ \rrbracket\end{array}$ & $\begin{array}{c}\text { SD: } 34.86 \\
\quad \dagger \neq\end{array}$ \\
\hline \multirow[b]{2}{*}{ Glucose (mg/dL) } & 125.1 & 195.1 & 123.2 & 191.9 \\
\hline & $\begin{array}{c}\text { SD: } 20.01 \\
\S \rrbracket\end{array}$ & $\begin{array}{c}\text { SD: } 29.65 \\
\quad †\end{array}$ & $\begin{array}{c}\text { SD: } 17.08 \\
\$ \rrbracket\end{array}$ & $\begin{array}{c}\text { SD: } 31.23 \\
\quad+\neq\end{array}$ \\
\hline \multirow[b]{2}{*}{$\mathrm{HDL}(\mathrm{mg} / \mathrm{dL})$} & 59.49 & 37.63 & 60 & 37.63 \\
\hline & $\begin{array}{c}\text { SD: } 9.65 \\
\text { \$ }\end{array}$ & $\begin{array}{c}\text { SD: } 10.96 \\
t \neq\end{array}$ & $\begin{array}{c}\text { SD: } 8.743 \\
\$ \rrbracket\end{array}$ & $\begin{array}{c}\text { SD: } 6.651 \\
t \neq\end{array}$ \\
\hline \multirow[b]{2}{*}{ LDL (mg/dL) } & 110 & 156 & 109.4 & 153.8 \\
\hline & $\begin{array}{c}\text { SD:8.862 } \\
\$ \rrbracket\end{array}$ & $\begin{array}{c}\text { SD: } 32.01 \\
\quad \dagger\end{array}$ & $\begin{array}{c}\text { SD: } 14.84 \\
\text { § }\end{array}$ & $\begin{array}{c}\text { SD: } 44.4 \\
\quad \dagger \neq\end{array}$ \\
\hline \multirow[b]{2}{*}{ VLDL (mg/dL) } & 24.79 & 39.24 & 26.19 & 39.24 \\
\hline & $\begin{array}{c}\text { SD: } 4.184 \\
\text { \$ף }\end{array}$ & $\begin{array}{l}\text { SD: } 7.06 \\
\quad \downarrow \neq\end{array}$ & $\begin{array}{c}\text { SD: } 4.311 \\
\S \rrbracket\end{array}$ & $\begin{array}{c}\text { SD: } 6.972 \\
\dagger \neq\end{array}$ \\
\hline \multirow[b]{2}{*}{ HDL/LDL ratio } & 0.5498 & 0.2533 & 0.5462 & 0.2555 \\
\hline & $\begin{array}{c}\text { SD:0.103 } \\
\$ \rrbracket\end{array}$ & $\begin{array}{c}\text { SD:0.098 } \\
t \neq\end{array}$ & $\begin{array}{c}\text { SD:0.087 } \\
\$ \rrbracket\end{array}$ & $\begin{array}{c}\text { SD:0.0769 } \\
\dagger \neq\end{array}$ \\
\hline \multirow[b]{2}{*}{ HDL/VLDL ratio } & 2.470 & 0.9726 & 2.364 & 0.9862 \\
\hline & $\begin{array}{c}\text { SD:0.588 } \\
\S \rrbracket\end{array}$ & $\begin{array}{c}\text { SD:0.299 } \\
\text { †‡ }\end{array}$ & $\begin{array}{c}\text { SD:0.577 } \\
\S \rrbracket\end{array}$ & $\begin{array}{c}\text { SD:0.241 } \\
+\neq\end{array}$ \\
\hline
\end{tabular}


Table I. Continuation.

\begin{tabular}{|c|c|c|c|c|}
\hline \multirow{3}{*}{ IL-17 (ng/mL) } & 0.5993 & 2.207 & 0.494 & 2.019 \\
\hline & SD: 1.223 & SD: 2.099 & SD: 0.666 & SD: 2.637 \\
\hline & $\S \rrbracket$ & $\dagger \ddagger$ & $\S \rrbracket$ & $\dagger \neq$ \\
\hline \multirow[b]{2}{*}{ IL-1 $\beta$ (pg/mL) } & 15.5 & 35.94 & 20.65 & 32.34 \\
\hline & SD: 13.76 & $\begin{array}{c}\text { SD: } 20.54 \\
\text { †キ }\end{array}$ & SD: 27.03 & $\begin{array}{c}\text { SD: } 25.5 \\
\dagger \neq\end{array}$ \\
\hline \multirow[b]{2}{*}{ TNF- $\alpha(\mathrm{ng} / \mathrm{mL})$} & 0.6044 & 3.142 & 0.4886 & 2.829 \\
\hline & $\begin{array}{c}\text { SD: } 0.857 \\
\S \emptyset\end{array}$ & $\begin{array}{c}\text { SD: } 2.123 \\
\text { †‡ }\end{array}$ & $\begin{array}{c}\text { SD: } 0.776 \\
\S \emptyset\end{array}$ & $\begin{array}{c}\text { SD: } 1.809 \\
\quad \dagger \neq\end{array}$ \\
\hline \multirow{2}{*}{ IL-10 (pg/mL) } & 145 & 20.77 & 101.2 & 30.37 \\
\hline & $\begin{array}{c}\text { SD:143.4 } \\
\S \rrbracket\end{array}$ & $\begin{array}{c}\text { SD: } 53.61 \\
\quad † \neq\end{array}$ & $\begin{array}{c}\text { SD:128.2 } \\
\S \rrbracket\end{array}$ & $\begin{array}{c}\text { SD:61.68 } \\
\quad † \neq\end{array}$ \\
\hline \multirow{2}{*}{ IFN-y (pg/mL) } & 2.806 & 6.118 & 3.253 & 6.267 \\
\hline & $\begin{array}{c}\text { SD:3.601 } \\
\S \rrbracket\end{array}$ & $\begin{array}{c}\text { SD:7.194 } \\
\quad \downarrow \neq\end{array}$ & $\begin{array}{c}\text { SD:3.554 } \\
\S \rrbracket\end{array}$ & $\begin{array}{c}\text { SD:8.208 } \\
\quad \downarrow \neq\end{array}$ \\
\hline \multirow{2}{*}{ IL-10/IL-17A } & 3731 & 103.2 & 1187 & 169.3 \\
\hline & SD:555 & $\begin{array}{c}\text { SD:303.0 } \\
十 \neq\end{array}$ & SD:3517 & $\begin{array}{c}\text { SD:663.0 } \\
\text { †キ }\end{array}$ \\
\hline \multirow[b]{2}{*}{ IL-10/IL-1 $\beta$} & 7.503 & 3.444 & 20.31 & 2.019 \\
\hline & $\begin{array}{c}\text { SD: } 13.65 \\
\$\end{array}$ & $\begin{array}{c}\text { SD: } 9.656 \\
\dagger \neq\end{array}$ & $\begin{array}{c}\text { SD: } 49.48 \\
\S 9\end{array}$ & $\begin{array}{c}\text { SD:4.743 } \\
\dagger \neq\end{array}$ \\
\hline \multirow[b]{2}{*}{ IL-10/IFN-Y } & 51.61 & 16.63 & 34.36 & 14.45 \\
\hline & $\begin{array}{c}\text { SD: } 99.22 \\
\S\end{array}$ & $\begin{array}{c}\text { SD: } 37.02 \\
+\end{array}$ & $\begin{array}{c}\text { SD: } 60.87 \\
\text { n }\end{array}$ & $\begin{array}{c}\text { SD: } 33.47 \\
\quad \dagger \neq\end{array}$ \\
\hline \multirow[b]{2}{*}{ IL-10/TNF- $\alpha$} & 175.9 & 26.36 & 95.33 & 42.00 \\
\hline & $\begin{array}{c}\text { SD: } 413.7 \\
\S \rrbracket\end{array}$ & $\begin{array}{c}\text { SD: } 33.93 \\
\dagger \neq\end{array}$ & $\begin{array}{c}\text { SD: } 140.6 \\
\S \rrbracket\end{array}$ & $\begin{array}{c}\text { SD: } 232.0 \\
\dagger \neq\end{array}$ \\
\hline
\end{tabular}

Physically active men $n=40$; Sedentary men $n=54$; Physically active women $n=98$;Sedentary women $n=184$. Differences were considered significant when $p$ value was less than 0.05 and, if detected, and was illustrated by: $\uparrow$ (When there are differences with the physically active men group); § (When there are differences with the sedentary men group); (When there are differences with the physically active women group); ๆ (When there are differences with thesedentary women group). SD: Standard deviation; WC: Waist circumference; BMI: Body mass index; MSP: mean blood systolic pressure; HDL: High density lipoprotein;LDL: Low density lipoprotein;VLDL: Very low density lipoprotein; 17A: Interleukin 17A;IL-1ß: Interleukin 1 beta;TNF- $\alpha$ : Tumor necrosis factor alpha;IL-10: Interleukin 10;IFN- $\mathrm{:} \mathrm{Interferon} \mathrm{gamma;mmHg:} \mathrm{millimeters} \mathrm{ofmercury;Kg:} \mathrm{kilogram;} \mathrm{kg/m²}$ Kilograms per square meter; \%:Percent; mg/dL: Milligram per deciliter; ng/mL: Nanogram per milliliter; pg/mL: Picogram per milliliter.

committed tophysical activity, for both men and women (Table I).

We also sought to compare the ratio between IL-10 and IL-1 $\beta$ or TNF- $\alpha$ or IL-17 or IFN-y in active or sedentary men and women. Men and women engaged inexercises exhibited higher ratio between IL-10 and all inflammatory cytokines previously mentioned (Table I). Nonetheless, physically active men seemed to have a much higher anti-inflammatory/inflammatory cytokine ratio in serum than physically active women, as IL-10/IL-17A ratio were 3.1 times higher in physically active men, followed by an increase in $\mathrm{IL}-10 / \mathrm{TNF}-\alpha$ ratio $(1.8 \mathrm{x})$ and $\mathrm{IL}-10 / \mathrm{IFN}-\mathrm{y}$ ratio (1.5x). 


\section{Men and women exhibited distinct patterns of multiple correlations among biochemical, anthropometric, and immune markers}

Along with the changes in serum concentrations of biochemical and immune markers, we also observed that each assessed group presented a distinct multiple correlation profile. People engaged in physical activity, for instance, had positive correlations between their mean blood systolic pressure (MSP) and fat mass, BMI, and their waist circumference/height ratio. Thus, both physically active men and women showed similar anthropometric profile. A negative correlation between the serum inflammatory marker TNF- $\alpha$ and HDL was noticed in all groups.

Hypertensive and diabetic women, regardless of physical activity, displayed a strong direct correlation between blood glucose levels and TNF- $\alpha$, likewise, IL-10 serum levels correlated with sera glucose levels in physically active women. In this group, a strong negative correlation $(p>0,001)$ between HDL and glucose is remarkable, however, a strong negative correlation $(p>0,001)$ between HDL and IL-10 was observed. Concerning to their synergy, IL-17 and TNF- $\alpha$ were positively correlated in men's blood sera, while IL-1 $\beta$ and TNF- $\alpha$ were positively correlated in all physically active groups. Sedentary men and women presented distinct triglyceride and VLDL correlations (Figure 1). In sedentary women, triglycerides and VLDL positively correlated with fat mass and were negatively associated with lean mass. Notably, both triglycerides and VLDL correlated with $\mathrm{BMI}$ in sedentary women and men, positively and negatively respectively. Overall, sedentary individuals exhibited a greater number of correlations between their sera biochemical markers than the group in exercises. It could be explained by the reduced serum concentrations of these markers in physically active people (Table I).

\section{DISCUSSION}

This research provides relevant information on the influence of gender on the body's responsiveness to physical activity, especially with regard to modulation in body composition and inflammatory balance in individuals with SAH and T2DM. In this work, although there are no statistical differences regarding drug treatment between men and women, specific differences were observed between genders. The lipid profile showed no gender-related differences in changes in concentrations due to physical activity. However, in sedentary women, these parameters seem to be more directly associated with modulations in body composition than in sedentary men, an important fact since these parameters are risk factors for T2DM and SAH. Active men showed a better anti-inflammatory balance when compared to active women. In addition, there were punctual differences in the way in which some cytokines such as IL10 relate to the other parameters in a genderdependent manner. Therefore, these results suggest that gender is related to a differential modulation of physical activity not only in the serum concentrations of biochemical and inflammatory markers, but also in the way they interact with each other and with the different systems in the physiological microenvironment in individuals with SAH and T2DM.

Body mass, usually expressed by the percentage of fat and lean mass, is an important predictor of the individual's health status and can be used as a predictor of chronic diseases, being essential the healthy control of these parameters (Sagun et al. 2014). In this study, we observed that hypertensive and diabetic men, regardless of physical activity, had lower values of fat mass than women did. This could be related to the fact that even active women presented a relevant overweight BMI. It is well 

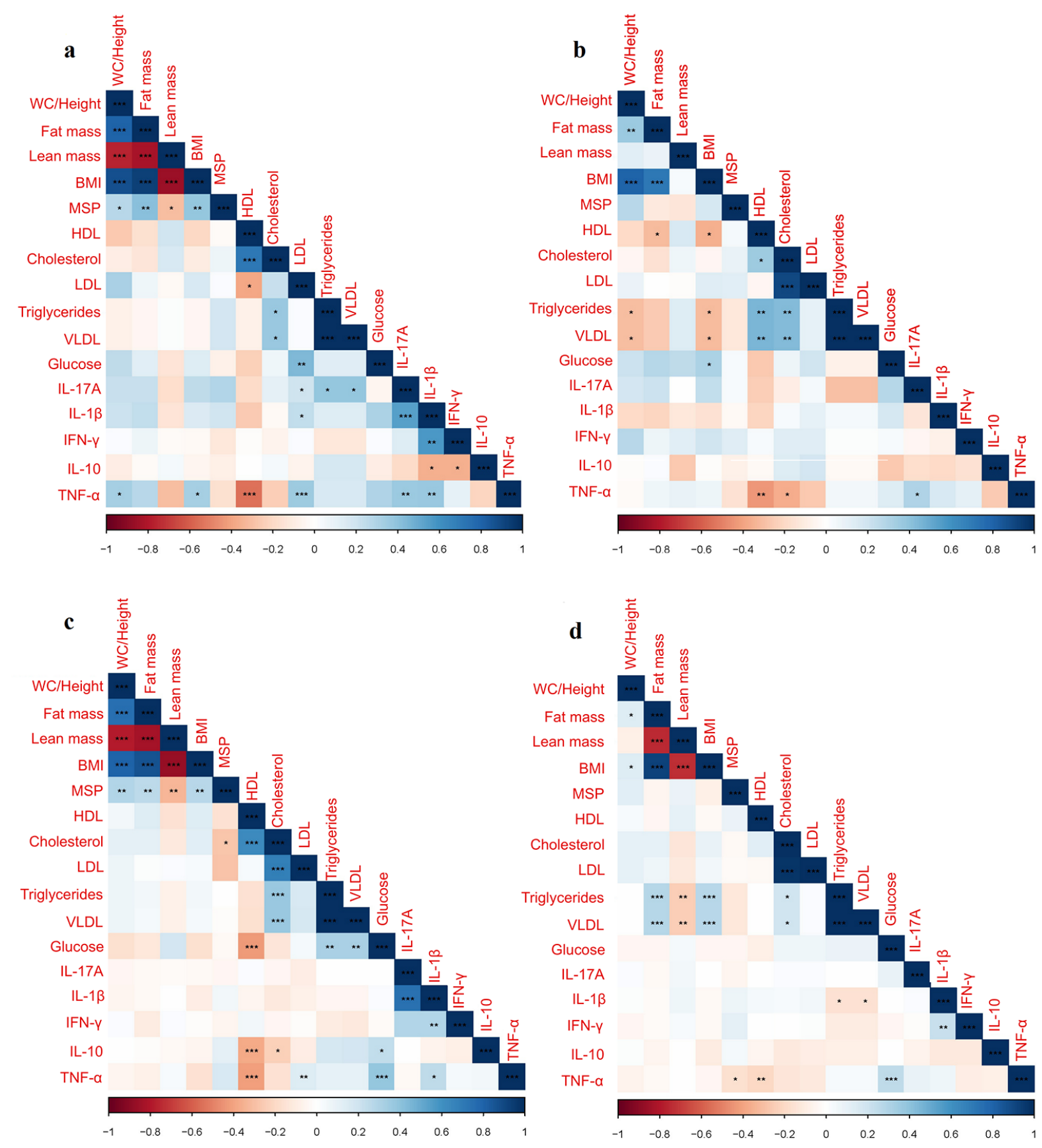

Figure 1. Correlations between anthropometric, blood pressure data, biochemical and immunological markers. a: Physically active men $(n=40)$; b: Sedentary men $(n=54) ;$ c: Physically active women $(n=98)$; d: Sedentary women $(n=184)$. Positive correlations are indicated in blue, and reverse correlations areindicated in red. Darker color tones indicate higher $r$ values. pvalues are indicated based on Spearman's rank correlation tests ${ }^{*} p<.05 ; * * p<.01$; *** $p<.001 ; * * * * p<.0001)$. Variable grouping is based on principal component analysis using the R packet corrplot.WC: Waist circumference; BMI: Body mass index; MSP: Mean systolic pressure. 
established that estrogen plays an important role in regulating body fat in women (Ahmadi et al. 2018). However, studies show that in obese women, many protective effects of estrogen are lost (McGill et al. 2011). This explains the fact that, despite being overweight, active women had better immunological and biochemical parameters when compared to sedentary women. In addition, women are generally more responsive to physical activity, even leisure time, to control fat mass, when compared to men (Ball et al. 2001). Thus, regardless of differences in the body fat accumulation profile, active women are more protected than sedentary men or women.

In a research carried out in Brazil with 15,105 participants of both genders, physically active or not (physically active $\geq 150$ minutes of physical activity/week of moderate physical activity), it was possible to observe that individuals who used to exercise exhibited lower serum levels of LDL, VLDL and triglycerides, accompanied by a higher concentration of serum HDL (Da Silva et al. 2016). Here, we were able to observe a reproduction of this result along with the detection of lower serum glucose values for individuals in physical activity. Moreover, this difference does not seem to be influenced by gender. Besides that, physically active individuals, regardless of sex, exhibited a stronger positive correlation between total and HDL cholesterol. It is well-defined that men and women exhibit a different lipoprotein metabolism throughout life, estrogen seems to influence the homeostasis of production and thereby serum concentration of lipoproteins in women (Soares et al. 2009). Here, sedentary and physically active women exhibited positive correlation between serum cholesterol and LDL. Physically active men, on the other hand, did not exhibit any correlation between LDL and cholesterol, only presenting a weak correlation between serum cholesterol levels and VLDL.
In this way, we demonstrate that men exhibit distinct profiles of correlations between serum lipoproteins than those in women.

Inflammatory cytokines are soluble markers that play an important role in the pathology of chronic noncommunicable diseases such as T2DM and SAH. A number of studies involving the application of physical activity have already reported the reduction of resting serum concentrations of inflammatory cytokines such as TNF- $\alpha$, IL-6 and IL-1 (Moon et al. 2017). Particularly in obese and overweight individuals, the practice of physical exercise (e.g., walking, running and jogging) contributed to the reduction of resting serum IL-1 $\beta$ levels probably by reducing fat mass (Olson et al. 2007). In fact, regardless of sex, individuals classified here as physically active ( $\geq 150$ minutes/week of physical activity) had lower restingserum concentrations of all inflammatory markers (IL-1 $\beta$, TNF- $\alpha$, IFN- $y$ and IL17). However, studies show that increased serum concentrations of pro-inflammatory molecules are predictive of frailty incidents in women, but not men (Gale et al. 2013). Therefore, although gender is not a determinant in the serum level of the analyzed proinflammatory cytokines, it is possible that their responsiveness to them is different between the genders. In this way, more studies are needed to clarify this issue. We have not been able to detect lower values of fat mass in body composition of women in exercise, even though their inflammatory serum cytokines concentrations were lower than the sedentary ones. This picture illustrates the multifactorial nature of physical activity influence on the production and serum concentration of inflammatory cytokines. Increased levels of glycaemia have been reported as a factor that stimulates the production of TNF- $\alpha$ by peripheral monocytes, then leading to spontaneous release of this inflammatory cytokine (Gonzalez et al. 2012). This fact highlights its clinical 
relevance in T2DM pathogenesis, especially in women, where we were able to encounter a positive correlation between fasting glycaemia and TNF- $\alpha$ serum levels, in both sedentary and physically active individuals. Interleukin-17A is an essential mucosal cytokine (Barin et al. 2016). Nevertheless, in this context, might act as an inflammation potentiator, contributing to intense vascular inflammation especially by its synergic action with TNF- $\alpha$, through the induction of further production of inflammatory cytokines and chemokines, as well as the expression of receptors, such as TNF receptor (Veldhoen 2017).

Interleukin-10 is an anti-inflammatory cytokine that exercises essential control over biochemical and immunological parameters, having an important protective role in diseases such as T2DM and SAH (Jung \& Choi 2014, Ribeiro et al. 2019). Its serum concentration is associated with increased skeletal muscle sensitivity to insulin and inhibition of inflammation in adipose tissue. Thus, it can contribute to glycemic control and regulation of the systemic inflammatory state associated with the pathogenesis of chronic non-communicable diseases (Hong et al. 2009). Interestingly, in this study, IL-10 showed different correlation patterns between active women and the other groups. In these women, from the observed correlations, IL-10 seems to participate more strongly in glycemic control. Such a pattern was not observed in active or sedentary men. Studies have shown that stimulation of the estrogen receptor modulates the secretion of IL-10 by inflammatory cells (Itoga et al. 2015). Furthermore, with increasing age, serum concentrations of IL-10 decrease more markedly in men than in women, showing that it varies in different ways depending on the individual's gender (Hirokawa et al. 2013). However, further studies are needed to assess whether glycemic control related to IL-10 has differences between genders. In addition, IL-10 is a potent inflammation modulator that directly inhibits the synthesis of inflammatory markers such as IL-1 $\alpha$, IL-1 $\beta$, TNF- $\alpha, I L-8$ and MIP-1 $\alpha$ (Nimmo et al. 2013). In our study, we observed that in physically active individuals there was a higher serum concentration of IL-10. In fact, physical activity is able to stimulate an increase in serum levels of IL-6, followed by an increase in serum levels of resting IL-10 (Petersen \& Pedersen 2005). Given its regulatory importance in maintaining inflammatory homeostasis, the relationship between serum concentrations of IL-10 with TNF- $\alpha$ and IL-17 was analyzed, and it was observed that, regardless of gender, physically active individuals exhibited higher proportions among IL-10 and markers. Thus, this molecule can and should contribute to the control of the chronic systemic inflammatory microenvironment of T2DM and SAH. However, although the IL-10 / TNF- $\alpha$ and IL-10 / IL-17A ratios seem superior in men, Ribeiro et al. (2019) observed that IL-17A and IL-10 have a relevant role associated with the modulation of risk factors inflammatory, biochemical and anthropometric in elderly women with SAH and T2DM. Thus, we postulate that the inflammatory modulation performed by IL-10/IL-17A associated with the pathophysiology of SAH and T2DM may be related to gender, but also to age.

All together, our findings indicate that there are gender-related differences in the modulation of anthropometric and biochemical characteristics by physical activity in hypertensive and diabetic individuals. Although exercise is clearly beneficial for reducing lipoproteins associated with increased cardiovascular risk, multiple correlation analyzes indicate a complex and gender-related relationship between physical activity and these lipoprotein markers. In addition, these gender-related correlations are also observed for inflammatory markers. However, despite being beneficial in both 
genders, it is possible that, depending on the gender, this modulation perpetrated through different control routes. Such knowledges are essential since once the main differences between the genders are identified, it is possible to determine personalized treatment methodologies, respecting the individual's particularities and enabling better results. However, further studies are needed involving parameters such as analysis of serum androgens and age in hypertensive and diabetic individuals, using models of amplified correlation analysis. Only in this way will it be possible to achieve a greater understanding of the complex relationship between physical activity and gender in the biochemical, inflammatory and anthropometric markers associated with the pathophysiology of hypertension and diabetes.

\section{Acknowledgments}

This work was supported by the Fundação de Amparo à Pesquisa do Estado da Bahia (FAPESB) and by Universidade Federal da Bahia - Instituto Multidisciplinar em Saúde - Campus Anísio Teixeira (UFBA-IMS-CAT) (Prodoc UFBA 04/2014). Some students involved in this study received Master and Doctoral scholarships from Fundação de Amparo a Pesquisa do Estado da Bahia (FAPESB), from Conselho Nacional de Desenvolvimento Científico e Tecnológico (CNPq) and from Coordenação de Aperfeiçoamento de Pessoal de Nivel Superior (CAPES), Brazil.

\section{REFERENCES}

AHMADI S, ESHRAGHIAN MR, HEDAYATI M \& PISHVA H. 2018. Relationship between estrogen and body composition, energy, and endocrine factors in obese women with normal and low REE. Steroids 130: 31-35.

AROOR AR, MANDAVIA CH \& SOWERS JR. 2012. Insulin Resistance and Heart Failure: Molecular Mechanisms. Heart Fail Clin 8(4): 609-617.

BALL K, OWEN N, SALMON J, BAUMAN A \& GORE CJ. 2001. Associations of physical activity with body weight and fat in men and women. Int J Obes 25: 914-919.
BARIN JG ET AL. 2016. Collaborative Interferon-y and Interleukin-17 Signaling Protects the Oral Mucosa from Staphylococcus aureus. Am J Pathol 186(9): 2337-2352.

CHEN L, MAGLIANO DJ \& ZIMMET PZ. 2011. The worldwide epidemiology of type 2 diabetes mellitus-present and future perspectives. Nat Rev Endocrinol 8(4): 228-236.

CHEUNG BMY \& LI C. 2012. Diabetes and Hypertension: IS There a Common Metabolic Pathway? CurrAtheroscler Rep 14(2): 160-166.

DA SILVA RC, DINIZ MFHS, ALVIM S, VIDIGAL PG, FEDELI LMG \& BARRETO SM. 2016. Physical Activity and Lipid Profile in the ELSA-Brasil Study. Arq Bras Cardiol 107(1): 10-19.

GALE CR, BAYLIS D, COOPER C \& SAYER AA. 2013. Inflammatory marker sand incident frailty in men and women: the English Longitudinal Study of Ageing. AGE 35: 2493-2501.

GONZALEZ Y, HERRERA MT, SOLDEVILA G, GARCIA-GARCIA L, FABIÁN G, PÉREZ-ARMENDARIZ EM, BOBADILLA K, GUZMÁN-BELTRÁN S, SADA E \& TORRES M. 2012. High glucose concentrations induce TNF- $\alpha$ production through the down-regulation of CD33 in primary human monocytes. BMC Immunol 13(1): 19.

HIROKAWA K, UTSUYAMA M, HAYASHI Y, KITAGAWA M, MAKINODAN T \& FULOP T. 2013. Slower immune system aging in women versus men in the Japanese population. Immun Ageing 10: 19 .

HONG EG ET AL. 2009. Interleukin-10 prevents diet-induced insulin resistance by attenuating macrophage and cytokine response in skeletal muscle. Diabetes 58(11): 2525-2535.

HU G, LINDSTRÖM J, VALLE TT, ERIKSSON JG, JOUSILAHTI P, SILVENTOINEN K, QIAO E \& TOUMILEHTO J. 2004. Physical Activity, Body Mass Index, and Risk of Type 2 Diabetes in Patients with Normal or Impaired Glucose Regulation. Arch Intern Med 164(8): 892-896.

ITOGA M ET AL. 2015. G-protein-coupled estrogen receptor agonist suppresses airway inflammation in a mouse model of asthma through IL-10. PLoS ONE 10(3): e0123210.

JUNG U \& CHOI MS. 2014. Obesity and its metabolic complications: the role of adipokines and the relationship between obesity, inflammation, insulin resistance, dyslipidemia and nonalcoholic fatty liver disease. Int J Mol Sci 15: 6184-6223.

KISSELA BM ET AL. 2012. Age at stroke: Temporal trends in stroke incidence in a large, biracial population. Neurology 79(17): 1782-1787.

LOPES WA, LEITE N, DA SILVA LR, BRUNELLI DT, GÁSPARI AF, RANDOMINSKI RB, CHACON-MIKAHIL MPT \& CAVAGLIERI CR. 2016. 
Effects of 12 weeks of combined training without caloric restriction on inflammatory markers in overweight girls. J Sports Sci 34(20): 1902-1912.

MARENGONI A, WINBLAD B, KARP A \& FRATIGLIONI L. 2008. Prevalence of chronic diseases and multimorbidity among the elderly population in Sweden. Am J Public Health 98(7): 1198-1200.

MATSUDO S, ARAÚJO T, MATSUDO V, ANDRADE D, ANDRADE E, OLIVEIRA LC \& BRAGGION G. 2001. International physical activity questionnaire (IPAQ): study of validity and reliability in Brazil. Rev Bras Ativ Fís Saúde 6: 5-18.

MCGILL JB, PETERSON LR, HERRERO P, SAEED IM, RECKLEIN C, COGGAN AR, DEMOSS AJ, SCHECHTMAN KB, DENCE CS \& GROPLER RJ. 2011. Potentiation of abnormalities in myocardial metabolism with the development of diabetes in women with obesity and insulin resistance. J Nucl Cardiol 18: 421-429.

MITTAL BV \& SINGH AK. 2010. Hypertension in the developing world: challenges and opportunities. Am J Kidney Dis 55(3): 590-598.

MOON S, SCHMIDT M, SMIRNOVA IV, COLGROVE Y \& LIU W. 2017. Qigong exercise may reduce serum TNF- $\alpha$ levels and improve sleep in people with Parkinson's disease: A pilot study. Medicines 4(2): 23.

NAG T \& GHOSH A. 2013. Cardiovascular disease risk factors in Asian Indian population: A systematic review. J Cardiovasc Dis Res 4(4): 222-228.

NIMMO MA, LEGGATE M, VIANA JL \& KING JA. 2013. The effect of physical activity on mediators of inflammation. Diabetes Obes Metab 15(3 Suppl): 51-60.

OLSON TP, DENGEL DR, LEON AS \& SCHMITZ KH. 2007. Changes in inflammatory biomarkers following one-year of moderate resistance training in overweight women. Int J Obes 31(6): 996-1003.

PETERSEN AMW \& PEDERSEN BK. 2005. The anti-inflammatory effect of exercise. J Appl Physiol 98(4): 1154-1162.

PRINCE MJ, WU F, GUO Y, ROBLEDO LMG, O'DONNELL M, SULLIVAN R \& YUSUF S. 2015. The burden of disease in older people and implications for health policy and practice. The Lancet 385(9967): 549-562.

RIBEIRO IS ET AL. 2019.Association between body composition and inflammation: A central role of IL-17 and IL-10 in diabetic and hypertensive elderly women. Exp Gerontol 127: 110734.

SAGUN G, OGUZ A, KARAGOZ E, FILIZER AT, TAMER G \& MESCI B. 2014. Application of alternative anthropometric measurements to predict metabolic syndrome. Clinics 69(5): 347-353.

SMAJLOVIĆ D. 2015. Strokes in young adults: Epidemiology and prevention. Vasc Health Risk Manag 11: 157-164.

SOARES GM, VIEIRA CS, DE PAULA MARTINS W, DOS REIS RM, DE SÁ MFS \& FERRIANI RA. 2009. Metabolic and cardiovascular impact of oral contraceptives in polycystic ovary syndrome. Int J Clin Pract 63(1): 160-169.

TIMMONS BW, HAMADEH MJ \& TARNOPOLSKY MA. 2006. NO effect of short-term $17 \beta$-estradiol supplementation in healthy men on systemic inflammatory responses to exercise. Am J Physiol Regul Integr Comp Physiol 291(2): R285-R290.

TRACHTA P ET AL. 2014. Three months of regular aerobic exercise in patients with obesity improve systemic subclinical inflammation without major influence on blood pressure and endocrine production of subcutaneous fat. Physiol Res 63(2Suppl): S299-S308.

VELDHOEN M. 2017. Interleukin 17 is a chief orchestrator of immunity. Nat Immunol 18(6): 612-621.

WEI T \& SIMKO V. 2013. Corrplot: Visualization of a correlation matrix. R package version 0.73 230(231): 11.

WIZEMANN TM \& PARDUE ML. 2001. Exploring the Biological Contributions to Human Health. Does Sex Matter? Washington (DC): National Academy Press, 288 p.

ZHONG J ET AL. 2014. T-cell costimulation protects obesityinduced adipose inflammation and insulin resistance. Diabetes 63(4): 1289-1302.

ZHOU H, YANG C, DONG C, GUO Z, HU X, XU Y \& ZHOU Z. 2014. Predictive Power for Type 2 Diabetes Mellitus using Dynamic Change of Metabolic Syndrome, Dynamic Change of Fasting Plasma Glucose, Metabolic Syndrome and Fasting Plasma Glucose. Iran J Public Health 43(4): 432-440.

\section{How to cite}

DOS SANTOS DC ET AL. 2021. Gender-related differences in the modulation of anthropometric, biochemical, and immune markers by physical activity in hypertensive and diabetic individuals. An Acad Bras Cienc 93: e20201905. DOI 10.1590/0001-3765202120201905.

\section{Manuscript received on December 10, 2020; accepted for publication on September 6, 2021}

\section{DÉBORAH C. DOS SANTOS ${ }^{1}$}

https://orcid.org/0000-0003-4880-6014 
ISRAEL S. RIBEIRO ${ }^{1,2}$

https://orcid.org/0000-0002-1262-1387

DIEGO PATRICK S. LOPES ${ }^{1}$

https://orcid.org/0000-0002-9211-5758

ÍTALO S. PEREIRA ${ }^{1}$

https://orcid.org/0000-0001-5697-5673

DENISAR P. SANTOS ${ }^{1}$

https://orcid.org/0000-0002-3930-9510

IGOR P.R. MUNIZ 1

https://orcid.org/0000-0003-1842-6432

FERNANDA M. DA SILVA LIMA ${ }^{1}$

https://orcid.org/0000-0001-9108-7831

ANDRESSA ANTÔNIA S. COSTA ${ }^{1}$

https://orcid.org/0000-0003-0079-7016

DANIELA DA SILVA P. SOUZA ${ }^{1}$

https://orcid.org/0000-0001-6050-433X

STÉFANO PEDRO DE MELO CALADO ${ }^{1}$

https://orcid.org/0000-0003-3458-1328

CAROLINE V. GONÇALVES ${ }^{1}$

https://orcid.org/0000-0003-0895-1583

MARIA POLIANA L. GALANTINI ${ }^{1}$

https://orcid.org/0000-0001-9423-5334

DANILO N. LOPES ${ }^{1}$

https://orcid.org/0000-0001-9473-9268

\section{ROBSON A.A. DA SILVA}

https://orcid.org/0000-0003-1361-1591

\section{GILVANÉIA S. SANTOS ${ }^{1}$}

https://orcid.org/0000-0002-5075-6872

${ }^{1}$ Instituto Multidisciplinar em Saúde, Campus Anísio Teixeira, Universidade Federal da Bahia, Rua Hormindo Barros, 58, Bairro Candeias, 45.029-094 Vitória da Conquista, BA, Brazil

${ }^{2}$ Universidade Federal do Sul da Bahia, Campus Paulo Freire, Praça Joana Angélica, 250, São José, 45988-058 Teixeira de Freitas, BA, Brazil

Correspondence to: Gilvanéia S. Santos

E-mail: gilsufba@gmail.com

\section{Author contributions}

Déborah C. Santos, Israel S. Ribeiro, Diego P.S. Lopes and Ítalo S. Pereira: conception and design, acquisition of data, analysis and interpretation of data and manuscript writing. Denisar P. Santos, Igor P.R. Muniz, Fernanda M.S. Lima, Andressa A.S. Costa, Daniela S.P. Souza, Stéfano P.M. Calado, Caroline V. Gonçalves and Maria P.L. Galantini: acquisition of data, analysis and interpretation of data. Danilo N. Lopes, Robson A.A. da Silva and Gilvanéia S. Santos: conception and design, analysis and interpretation of data.

\section{(cc) BY}

